\title{
Left atrial and left atrial appendage systolic function in patients with post-myocardial distal blocks
}

Grzegorz Piotrowski ${ }^{1}$, Piotr Szymański ${ }^{1}$, Maciej Banach², Aneta Piotrowska³, Rafał Gawor ${ }^{1}$, Jacek Rysz ${ }^{3}$, Zenon Gawor ${ }^{1}$

1Department of Cardiology, M. Kopernik Specialist District Hospital, Lodz, Poland 2Department of Hypertension, Medical University of Lodz, Poland

${ }^{3}$ Department of Nephrology, Hypertension and Family Medicine, Medical University of Lodz, Poland

Submitted: 11 February 2010

Accepted: 24 December 2010

Arch Med Sci 2010; 6, 6: 892-899

DOI: 10.5114/aoms.2010.19298

Copyright (C) 2010 Termedia \& Banach

\section{Abstract}

Introduction: The study aimed to evaluate function of the left atrium (LA) and of the left atrial appendage (LAA) after myocardial infarction (MI) complicated by intracardiac conduction disturbances.

Material and methods: The study comprised 59 patients with persistent postmyocardial distal blocks, who were allocated to one of the three following subgroups: study group I- 20 patients with left bundle branch block (LBBB); study group II - 20 patients with right bundle branch block (RBBB), and study group III -19 pts with left anterior hemiblock (LAHB). The control groups included patients with $\mathrm{MI}$ in their history and no BBBs (19 pts - group IV) and clinically healthy people (16 patients - group V). The parameters of LA and LAA systolic function were determined by means of transthoracic (TTE) and transoesophageal echocardiography (TOE).

Results: We showed that patients who experienced myocardial infarction not complicated with conduction disturbances expressed compensatory LA systolic function enhancement. In patients with post-myocardial RBBB and LAHB significant enhancement of LA systolic function was observed as well but it was expressed to a lesser degree. There was also a tendency towards deterioration of LA systolic function in patients with post-myocardial LBBB. LBBB did not affect LAA systolic function negatively.

Conclusions: Parameters of LAA systolic function showed its enhancement in all patients after myocardial infarction irrespective of whether it was complicated by conduction disturbances.

Key words: left atrium, left atrial appendage, echocardiography, distal blocks

\section{Introduction}

The cardiac conduction system is responsible for generation and conduction of synchronized bioelectric stimuli in the heart, which results in coordinated physiological and effective heart work. Defects of this system affect and deteriorate left and right ventricular as well as atrial function [1-3].

Bundle branch blocks (BBBs) are known to be associated with higher mortality in patients with acute myocardial infarction (MI) and with congestive heart failure (CHF) [4-8]. There are limited data on the influence of BBBs on prognosis in ischaemic heart disease. BBBs are the cause of

\section{Corresponding author:}

Grzegorz Piotrowski, MD, PhD

Department of Cardiology

M. Kopernik Specialist District Hospital

ul. Pabianicka 62

93-519 Lodz, Poland

Phone: +48 607244594

E-mail: gpiotr4@wp.pl 
left and right ventricular systolic and diastolic function deterioration $[9,10]$. Little is known about left atrial function and about left atrial appendage function in patients with post-myocardial BBBs.

It is known that left atrial (LA) systolic function is enhanced in hypertension [11], in CHF [12, 13], and post MI [14]. LA and left atrial appendage (LAA) function may be a useful indicator of the degree of left ventricular (LV) impairment and may determine the prognosis [15-22].

Poor physical efficiency, impaired LV function and intraventricular conduction prolongation are classical, well established indications for cardiac resynchronised therapy (CRT) [23]. But better, more efficient criteria for CRT are still being sought.

The degree of LA and LAA function impairment might become in future useful clues to qualify patients with CHF for CRT.

As we know there have been no clinical studies on the mutual interaction between BBBs and LA and LAA function. That is why we assessed and compared LA and LAA systolic function in patients with post-myocardial left bundle branch block (LBBB), right bundle branch block (RBBB) and left anterior hemiblock (LAHB), and compared the data to those of patients after MI with no conduction disturbances as well as to healthy subjects.

\section{Material and methods}

\section{Study population}

The study group comprised 59 patients with persistent post-myocardial distal blocks. They were allocated to one of the three following subgroups: study group I - 20 patients with LBBB; study group II - 20 patients with RBBB; study group III - 19 patients with LAHB. Control groups consisted of patients with $\mathrm{Ml}$ in their history and no intracardiac conduction disturbances (19 patients - group IV) and clinically healthy people (16 patients - group V).

Patients with BBBs other than post-myocardial aetiology were not entered into the study. The patients were included only if they had had ECG records done within 6 months before $\mathrm{MI}$ and had no BBBs. That made it highly probable that conduction disturbances were the effects of MI. Patients with congenital and significant valvular anomalies, with heart rhythm disturbances, with acute and chronic pulmonary disease, with anaemia, with hypo- and hyperthyreosis and with neoplastic diseases were excluded from the study. Patients with echocardiographically documented ventricular hypertrophy were not admitted to the study either.

The study protocol was approved by the Ethics Committee of the Medical University of Lodz, Poland. All patients signed informed consent prior to inclusion in the study.

\section{Echocardiography}

All enrolled patients underwent transthoracic and transoesophageal echocardiography. Investigations were performed with a 1.7-3.5 MHz transducer (Acuson) connected to an Acuson Sequoia 512 and with a multiplane transducer $5.5 \mathrm{MHz}$ connected to the same echocardiography system. Each parameter was calculated twice and the averaged values were analysed.

\section{Transthoracic echocardiography}

The routine parasternal long and short axis views as well as four-chamber and two-chamber views were used to measure the parameters. Simultaneously to echocardiography one ECG lead record was performed.

\section{M-mode echocardiography (left atrial parameters)}

From $\mathrm{M}$-mode in parasternal long axis view the following parameters of the left atrium were measured: (1) LA maximum dimension ( $L A_{\text {max. }}$ ), measured just after the T wave, (2) LA minimum dimension ( $\left(\mathrm{A}_{\min }\right)$, measured just before the QRS complex, (3) LA pre-systolic dimension ( $\left.L A_{a}\right)$, measured at the peak of the $P$ wave of the simultaneously recorded ECG [24].

On the basis of these three parameters the following four LA indexes describing its haemodynamic function were calculated $[24,25]$.

Active emptying fraction of LA (FAE LA):

$$
F A E L A=\frac{L A_{a}-L A_{\text {min. }}}{L A_{a}}
$$

Passive emptying fraction of LA (FPE LA):

$$
\text { FPE LA }=\frac{L A_{\text {max. }}-L A_{a}}{L A_{\max } .}
$$

Total emptying fraction of LA (FT LA):

$$
\text { FTE LA }=\frac{L A_{\text {max. }}-L A_{\text {min. }}}{L A_{\max } .}
$$

Echocardiographic parameters of LA:

2D LA parameters: $L A_{\text {infero-posterior, }} \mathrm{LA}_{\text {medio-lateral }}{ }^{-}$ dimensions measured in four-chamber apical view at the end of the LA systole.

Multiplying the latter two dimensions by each other $\left(\mathrm{LA}_{\text {infero-posterior }} \times \mathrm{LA}_{\text {medio-lateral }}\right) \mathrm{LA}$ area was calculated ( $\left.L A_{\text {area }}\right)$.

Doppler parameters of LA function:

From trans-mitral flow the following parameters were determined by means of pulsed Doppler method:

PEP LA - pre-ejection period of LA - time interval measured from the beginning of the P-wave in 
simultaneously recorded ECG to the beginning of the A (atrial) wave in pulsed Doppler spectrum power of transmitral flow.

ET LA ejection time of LA - time interval between the beginning and the end of the A (atrial) wave in pulsed Doppler spectrum power of transmitral flow.

PEP/ET LA index - calculated as PEP LA/ET LA [25-26].

\section{Pulmonary venous flow parameters}

The flow in the upper right pulmonary vein was analysed. The pulsed Doppler sample volume was placed 0.5 to $1.0 \mathrm{~cm}$ in the orifice of the upper right pulmonary vein into the left atrium. The vein was visualized by a slightly cephalic elevation of the interrogation plane from a standard four-chamber view. We analysed peak velocity of retrograde (PVR) (atrial) pulmonary venous flow $[29,30]$ as the parameter describing LA systolic function.

Transthoracic echocardiography 2D left ventricular parameters: LVEDd - left ventricular enddiastolic volume, LVESd - left ventricular endsystolic volume, LVEF - left ventricular ejection fraction, measured according to Simpson's formula.

\section{Transthoracic Doppler echocardiography of mitral flow}

Mitral flow was recorded between the mitral leaflets in the four-chamber view. The following parameters were analysed from the velocity tracings: $\mathrm{E}$ - early mitral flow peak velocity, A - atrial flow peak velocity, DT - deceleration time of E wave, E/A - early mitral/atrial flow peak velocities index [31], IVRT - isovolumic relaxation time of left ventricle.

\section{Transoesophageal echocardiography left atrial} appendage parameters

The following LAA parameters were analysed: - LAA transversal dimension $\left(\mathrm{LAA}_{\text {trans. }}\right)$ i.e.

- LAA longitudinal dimension (LAA long. $_{\text {) }}$ i.e.

- LAA maximal ( $L A A_{\text {area max. }}$ ) i.e. diastolic area measured at the onset of $P$ wave of ECG

LAA minimal ( $\mathrm{LAA}_{\text {area min. }}$ ) i.e. systolic area measured just after $R$ wave of QRS complex of ECG [32].

The LAA ejection fraction ( $\mathrm{EF}_{\mathrm{LAA}}$ ) was calculated as maximal area minus minimal area divided by the maximal area:

$$
E F_{L A A}=\frac{L A A_{\text {max. area }}-L A A_{\text {min. area }}}{L A A_{\text {max. area }}}
$$

The LAA blood flow velocity was obtained by placing the pulsed Doppler sample volume into the outlet of the appendage blood cavity $>1 \mathrm{~cm}$ away from the left atrial cavity. The peak LAA emptying
(LAAE) and the peak LAA filling (LAAF) velocities were recorded as described previously [33-35]. LAAE [m/s]-left atrial appendage (LAA) peak emptying velocity was obtained in the left atrial appendage long-axis view with the sample volume placed 0.5$1.0 \mathrm{~cm}$ within the appendage outlet.

LAAF $[\mathrm{m} / \mathrm{s}]$-LAA peak filling velocity - measured in the same way as LAAE.

\section{Statistical analysis}

Data are reported as mean \pm SD. A $p$-value $<0.05$ was considered significant. The following tests for statistical significance were used: (1) for dependent variables: Student's $t$-test if the distribution was normal, Wilcoxon's test if the distribution of at least one of the characters differed from normal, (2) for independent variables: Student's $t$-test if the variances were equal and the distribution of the character was normal, Cochran's test if the variances were not equal and the distribution of the character was normal, Mann-Whitney test or KolmogorovSmirnov test if the distribution of at least one of the characters differed from normal. The KolmogorovSmirnov test was used to assess whether the distribution of the analysed character was normal.

\section{Results}

Study group I - comprised 13 women and 7 men aged from 53 to 77 years (mean $67.6 \pm 9.96$ ). Study group II: 9 women and 11 men aged from 52 to 85 years (mean $71.4 \pm 8.88$ ). Study group III: 4 women and 15 men aged from 54 to 79 years (mean $68.95 \pm 9.24$ ). Every patient experienced MI at least 6 weeks before inclusion in the study and had the proper level of myocardial necrosis markers (creatine kinase-MB fraction [CK-MB] and troponins) at the time of inclusion. In group I 15 patients had anterior, 3 infero-lateral MI. In group II 12 patients had anterior; 2 antero-lateral; 4 lateral; 2 inferior MI. In group III 8 patients had anterior; 9 inferior and 3 lateral MI. All patients had sinus rhythm in ECG Holter monitoring. Sinus rhythm was necessary to be included in the study.

Forty-two patients had hyperlipidaemia, 36 hypertension, 27 were addicted smokers, 22 had positive family history, 3 diabetes mellitus (DM) type 2 and 4 obesity. A precise description of the risk factors in particular groups is presented in Table I.

Groups IV and V constituted control groups. Patients of group IV (16) experienced MI at least 6 weeks before inclusion in the study and had no His-Purkinje system disturbances. All the individuals had q-wave MI; 7 anterior; 5 inferior; 3 lateral; 1 apical MI. There were 10 men and 6 women in the group aged from 45 to 96 years (mean 63.94 $\pm 12.75)$. Group $\vee$ comprised 14 clinically healthy people: 8 men and 6 women, aged from 24 to 69 
Table I. Clinical characteristics of study groups

\begin{tabular}{|lcccccc|}
\hline & Group I & Group II & Group III & Group IV & Group V & All \\
\hline Dyslipidaemia & 12 & 11 & 5 & 11 & 3 & 42 \\
\hline Hypertension & 13 & 10 & 6 & 7 & 0 & 36 \\
\hline Smoking & 8 & 9 & 4 & 5 & 1 & 27 \\
\hline Positive family history & 7 & 8 & 4 & 2 & 1 & 22 \\
\hline Obesity & 1 & 1 & 2 & 0 & 0 & 4 \\
\hline Diabetes mellitus & 1 & 1 & 0 & 1 & 0 & 3 \\
\hline
\end{tabular}

(medium $43.79 \pm 12.23$ ). They had no significant changes in the coronary arteries.

LAmax., LAmin., and LAa were significantly higher in groups I-IV than in group V. But they did not differ significantly between groups I-IV. There were no significant differences as to FAE LA and FPE LA between groups I-V. The values of FTE LA in groups II and III were significantly higher than in group V. All the results are presented in Tables II-IV.

E was significantly higher in group I than in groups II, III, IV, did not differ from group V, while the values in groups II, III, IV were significantly lower than in group $V$. A was significantly higher in groups II, III, IV than in group V. A in group I did not significantly differ from other groups. E/A ratio was significantly lower in groups II and IV than in group V. DT was significantly shorter in groups II and III than in group IV, and significantly longer in group IV than in group $\mathrm{V}$.
PEP LA was significantly longer in group I than in groups III and IV while it was significantly shorter in groups III and IV than in group V. ET LA was significantly shorter in group IV and it was significantly longer in groups III and IV than in group V. In group II ET was significantly longer than in group $\mathrm{V}$, significantly shorter than in group IV, and did not differ from the other groups. PEP/ET LA index was significantly higher in group I than in groups III and IV, and in group II as compared with IV. It was significantly lower in groups II, III, IV than in group V.

PVR was significantly higher in groups I, II, III, IV than in group $\mathrm{V}$.

\section{Parameters of LAA systolic function}

LAA $_{\text {trans. }}$ was significantly higher in group I than in group $\mathrm{V}$. $L A A_{\text {long. }}$ was significantly higher in group I than in groups II, III, V and it was significantly

Table II. Echocardiographic parameters of left atrium

\begin{tabular}{|c|c|c|c|c|c|}
\hline & Group I & Group II & Group III & Group IV & Group V \\
\hline $\mathrm{LA}_{\max .}[\mathrm{cm}]$ & $3.85 \pm 0.64 V$ & $3.74 \pm 0.44^{V}$ & $3.76 \pm 0.42^{V}$ & $3.77 \pm 0.44 \mathrm{~V}$ & $3.13 \pm 0.40$ \\
\hline $\mathrm{LA}_{\min .}[\mathrm{cm}]$ & $2.69 \pm 0.78^{V}$ & $2.65 \pm 0.44^{\vee}$ & $2.70 \pm 0.58^{V}$ & $2.50 \pm 0.62^{V}$ & $2.05 \pm 0.31$ \\
\hline $\mathrm{LA}_{\mathrm{a}}[\mathrm{cm}]$ & $3.25 \pm 0.72^{V}$ & $3.12 \pm 0.49 \mathrm{~V}$ & $3.26 \pm 0.47 \mathrm{~V}$ & $3.06 \pm 0.52 \mathrm{~V}$ & $2.54 \pm 0.32$ \\
\hline FAE & $0.18 \pm 0.11$ & $0.17 \pm 0.09$ & $0.15 \pm 0.08$ & $0.19 \pm 0.09$ & $0.19 \pm 0.07$ \\
\hline FPE & $0.16 \pm 0.08$ & $0.17 \pm 0.08$ & $0.14 \pm 0.05^{\mathrm{IV} . \mathrm{V}}$ & $0.19 \pm 0.09$ & $0.19 \pm 0.05$ \\
\hline FTE & $0.31 \pm 0.11$ & $0.29 \pm 0.09 \mathrm{~V}$ & $0.28 \pm 0.10^{V}$ & $0.35 \pm 0.10$ & $0.35 \pm 0.06$ \\
\hline $\mathrm{E}[\mathrm{m} / \mathrm{s}]$ & $0.82 \pm 0.26$ II IIII. IV & $0.62 \pm 0.20^{V}$ & $0.65 \pm 0.17 \mathrm{~V}$ & $0.66 \pm 0.17 \mathrm{~V}$ & $0.80 \pm 0.12$ \\
\hline $\mathrm{A}[\mathrm{m} / \mathrm{s}]$ & $0.76 \pm 0.32$ & $0.78 \pm 0.22 \mathrm{~V}$ & $0.80 \pm 0.27 \mathrm{~V}$ & $0.77 \pm 0.26 \mathrm{~V}$ & $0.57 \pm 0.14$ \\
\hline E/A & $1.28 \pm 0.75$ & $0.90 \pm 0.49 \mathrm{~V}$ & $1.03 \pm 0.90$ & $0.93 \pm 0.35^{V}$ & $1.45 \pm 0.33$ \\
\hline DT [ms] & $177.75 \pm 78.54$ & $157.52 \pm 69.67 \mathrm{IV}$ & $159.53 \pm 86.93 \mathrm{IV}$ & $221.69 \pm 74.31^{V}$ & $162.07 \pm 12.48$ \\
\hline IVRT [ms] & $103.35 \pm 39.51$ & $98.30 \pm 29.96$ & $107.47 \pm 34.51$ & $101.13 \pm 27.92$ & $90.21 \pm 16.08$ \\
\hline PEPLA [ms] & $88.40 \pm 46.97$ III. IV & $71.60 \pm 28.49$ & $62.88 \pm 14.54 \mathrm{~V}$ & $62.20 \pm 15.09 \mathrm{~V}$ & $76.57 \pm 12.04$ \\
\hline $\mathrm{ET}[\mathrm{ms}]$ & $145.90 \pm 49.57 \mathrm{IV}$ & $154.35 \pm 33.69 \mathrm{gl} . \mathrm{V}$ & $173.32 \pm 67.69 \mathrm{~V}$ & $189.94 \pm 48.50 \mathrm{~V}$ & $128.43 \pm 15.93$ \\
\hline PEP/ET & $0.66 \pm 0.44$ III. IV & $0.48 \pm 0.19 \mathrm{IV} . \mathrm{V}$ & $0.41 \pm 0.18 \mathrm{~V}$ & $0.35 \pm 0.12^{V}$ & $0.60 \pm 0.11$ \\
\hline PVR $[\mathrm{m} / \mathrm{s}]$ & $0.33 \pm 0.14 \mathrm{~V}$ & $0.35 \pm 0.13^{V}$ & $0.35 \pm 0.11^{V}$ & $0.31 \pm 0.09 \mathrm{~V}$ & $0.19 \pm 0.02$ \\
\hline
\end{tabular}

$L A_{\text {max. }}$ - $L A$ maximum dimension, $L A_{\text {min. }}$ - $L A$ minimum dimension, $L A_{a}-L A$ pre-systolic dimension, $F A E$ - active emptying fraction of $L A$, $F P E$ - passive emptying fraction of $L A, F T E$ - total emptying fraction of $L A, E$ - early mitral flow peak velocity, $A$ - atrial flow peak velocity $D T$ - deceleration time, IVRT - isovolumic relaxation time of left ventricle, PEPLA - pre-ejection period of $L A$, ET - ejection time of $L A$, $P E P / E T$ - PEP/ET index, PVR - peak velocity of retrograde (atrial) pulmonary venous flow

II, III, IV,V - Group number under a parameter value indicates significant difference with that group. Statistical significance $p<0.05$ 
Table III. Echocardiographic parameters of left atrial appendage

\begin{tabular}{|c|c|c|c|c|c|}
\hline & Group I & Group II & Group III & Group IV & Group V \\
\hline $\mathrm{LAA}_{\text {long }}[\mathrm{cm}]$ & $4.37 \pm 0.72^{\mathrm{V}}$ & $3.75 \pm 0.69$ & $3.63 \pm 1.03$ & $3.60 \pm 1.01$ & $3.11 \pm 0.69$ \\
\hline $\mathrm{LAA}_{\text {trans }}[\mathrm{cm}]$ & $1.59 \pm 0.39$ II. III. V & $1.53 \pm 0.53^{V}$ & $1.56 \pm 0.38$ & $1.6 \pm 0.26$ & $1.32 \pm 0.25$ \\
\hline $\mathrm{LAA}_{\text {area max. }}\left[\mathrm{cm}^{2}\right]$ & $4.41 \pm 1.67 \mathrm{~V}$ & $3.8 \pm 1.43$ & $3.43 \pm 1.91$ & $3.58 \pm 2.56$ & $3.1 \pm 0.87$ \\
\hline $\mathrm{LAA}_{\text {area min. }}\left[\mathrm{cm}^{2}\right]$ & $1.79 \pm 1.08$ & $1.3 \pm 0.94$ & $1.34 \pm 1.27$ & $1.54 \pm 1.35$ & $2.08 \pm 0.68$ \\
\hline EFLAA [\%] & $47.37 \pm 17.91^{11 .}$ V & $33.7 \pm 13.67 \mathrm{~V}$ & $35.99 \pm 17.91^{V}$ & $39.45 \pm 9.55 \mathrm{~V}$ & $33.29 \pm 8.28$ \\
\hline LAAE $[\mathrm{m} / \mathrm{s}]$ & $0.74 \pm 0.22^{1 I . V}$ & $0.53 \pm 0.23$ & $0.57 \pm 0.35$ & $0.81 \pm 0.06 \mathrm{~V}$ & $0.41 \pm 0.04$ \\
\hline LAAF $[\mathrm{m} / \mathrm{s}]$ & $0.61 \pm 0.18$ II. III. V & $0.44 \pm 0.12$ & $0.44 \pm 0.21$ & $0.49 \pm 0.06$ & $0.42 \pm 0.05$ \\
\hline
\end{tabular}

$L A A_{\text {long. }}$ - left atrial appendage longitudinal dimension, $L A A_{\text {trans }}$ - left atrial appendage transversal dimension, $L A A_{\text {area max. }}-$ left atrial appendage maximal area, $L A A_{\text {area min. }}$ - left atrial appendage minimal area, EFLAA - left atrial appendage ejection fraction, $L A A E$ - left atrial appendage maximal empting velocity, LAAF - left atrial appendage maximal filling velocity

$I I, I I, I V, V$ - Group number under a parameter value indicates significant difference with that group. Statistical significance $p<0.05$

Table IV. Left ventricular parameters

\begin{tabular}{|lccccc|}
\hline & Group I & Group II & Group III & Group IV & Group V \\
\hline LVEDd [cm] & $5.56 \pm 0.82^{\mathrm{V}}$ & $5.54 \pm 0.95 \mathrm{~V}$ & $5.44 \pm 0.89$ & $5.47 \pm 0.67 \mathrm{~V}$ & $4.92 \pm 0.43$ \\
\hline LVESd [cm] & $4.26 \pm 0.80^{\mathrm{IV}} \mathrm{V}$ & $4.06 \pm 1.29 \mathrm{~V}$ & $3.7 \pm 1.05 \mathrm{~V}$ & $3.57 \pm 0.72 \mathrm{~V}$ & $2.76 \pm 0.43$ \\
\hline LVEF [\%] & $34.75 \pm 11.59 \mathrm{IV} . \mathrm{V}$ & $40.3 \pm 9.58^{\mathrm{IV}} \mathrm{V}$ & $37.53 \pm 8.85$ IV.V & $47.25 \pm 9.66 \mathrm{~V}$ & $58.83 \pm 4.85$ \\
\hline
\end{tabular}

LVEDd - left ventricular end-diastolic dimension, LVESd - left ventricle end-systolic dimension, LVEF - left ventricular ejection fraction $\mathrm{IV}, V$ - Group number under a parameter value indicates significant difference with that group. Statistical significance $p<0.05$

higher in group II than in group V. LAA area max. was significantly higher in group I than in group $\mathrm{V}$. $L_{A A} A_{\text {area min. }}$ was significantly lower in group III than in $\mathrm{V}$.

$\mathrm{EF}_{\text {LAA }}$ was significantly higher in groups I, II, III, IV than in group $V$ and it was significantly higher in group I than in group II.

LAAE was significantly higher in group I than in groups II and V as well as in group IV than in group V. LAAF was significantly higher in group I than in groups II, III, V.

LVEDd was significantly higher in groups I, II, IV than in group V. LVESd was significantly higher in groups I, II, III, IV than in group V; it was also significantly higher in group I than in group IV. EF was significantly lower in groups I, II, III, IV than in group V. In groups I, II, III EF was significantly lower than in group IV.

\section{Discussion}

Echocardiography is a widely used and accepted method for LA function evaluation. In the study we assessed systolic LA and LAA function in patients after MI complicated with BBBs.

As far as we know, nobody has investigated LA and LAA systolic function in post-MI BBBs in a clinical context until now.

Our findings indicate that LA compensates LV deterioration after $\mathrm{MI}$, but the presence of postmyocardial intra-ventricular conduction disturbances impairs the compensatory mechanisms. The more advanced conduction disturbances were observed, the more was compensation impaired. In patients who had $\mathrm{MI}$ with no conduction disturbances in the His-Purkinje system the LA systolic function enhancement was most expressed. The compensatory mechanism was also observed in patients with post-myocardial LAHB and RBBB but to a far lesser degree. Analysis of echocardiographic parameters showed no enhancement but rather a tendency towards deterioration of LA systolic function in patients with post-myocardial LBBB (group I) as compared to healthy individuals (group V).

It is widely known that the LA contributes as a pump in the LV filling increase after $\mathrm{MI}$ and this is a compensatory mechanism to LV function deterioration due to post-infarction myocardial damage [36-38]. LA and LV function are strictly associated with each other - they cooperate mutually. There are observations that LV function deterioration results in LA systolic function enhancement [37]. It happens in congestive heart failure as after $\mathrm{MI}$ [39] and in congestive cardiomyopathies. The LA works as a "booster pump", compensating LV systolic function loss to support cardiac output [38].

The enhancement of LA systolic function was observed in patients with post-myocardial RBBB and LAHB (group II and group III), as compared to healthy individuals (group V).

There is evidence that LV function is impaired in patients with LBBB as compared with individuals 
with no conduction disturbances [41]. LBBB is associated with higher LVEDd, lower EF, and longer IVRT $[1,41]$. These indicate that LBBB affects systolic as well as diastolic function. In our study the parameters of LV systolic function (LVEDV, LVESd, EF) showed significantly worse LV systolic function in patients with BBBs as compared with subjects after MI and no conduction disturbances (group IV) as well as compared with healthy subjects (group V). But there were no significant differences in LV systolic function parameters between groups of patients with different conduction disturbances. Meanwhile, most parameters describing LA systolic function showed significant differences between analysed groups of patients. Generally speaking, patients with post-MI RBBB and LAHB had more enhanced $L A$ systolic function than patients with post-MI LBBB.

We conclude that LA systolic function and the parameters describing it are probably more sensitive than LV systolic function and its parameters to heart overload. That is why despite no significant differences among LV function parameters in patients with RBBB and $L A H$, the parameters of LA presented less enhanced systolic function in patients with RBBB compared with $\mathrm{LAH}$.

According to the results of our study the compensatory mechanism of LA enhancement that occurs in response to LV function impairment seems to be reduced by intracardiac conduction disturbances. The more severely conductance was impaired the more the effect of diminishing of the LA compensation in LA systolic parameters was visible. In patients with post-MI LBBB LA systolic function was observed not to be enhanced but it showed even a tendency to be deteriorated as compared with patients who had $\mathrm{Ml}$ with no conductance disturbances. In patients with postMI RBBB and LAHB enhancement of LA systolic function seemed to have been less expressed than in patients with $\mathrm{MI}$ and no BBBs. RBBB and $\mathrm{LAHB}$ reduced $L A$ systolic compensation but definitely to a lesser degree than LBBB.

Conductance disturbances in the His-Purkinje system resulting from $\mathrm{Ml}$ are additional factors, together with post-myocardial scar, that impair left ventricular function. In our study, patients with post-MI LBBB had the worst LV systolic function (the lowest EF). In these patients LA systolic function could have been expected to be mostly enhanced. However, we observed the contrary phenomenon.

LV impairment causes LV end diastolic pressure to increase. The pressure in the LA chamber increases as well. The LA like the LV works according to Frank-Starling's law. LA contraction is determined by the length of the atrial fibres, i.e. by the pressure existing in the LA chamber just prior to its systole
[42-44]. During ventricular diastole, the LA is directly exposed to LV pressures through the open mitral valve [45]. The higher the LA pressure, the stronger the LA muscle fibre contractions and the greater the volume expelled from the LA to the LV chamber. However, this compensatory mechanism is limited to some degree. If the LA pressure exceeds the higher limit of Frank-Starling's law the compensatory mechanisms fail [24, 46]. In patients with LBBB LV function was impaired the most severely, which resulted in the highest LV end diastolic and LA pressure. The values of LA pressure might have exceeded the upper limit within which Frank-Starling's law operates.

Another explanation of the observed reduction of LA compensation in post-MI LBBB might be the fact that BBBs disrupt LA and LV mutual haemodynamic cooperation. The effectiveness of atrial systole in augmenting ventricular output depends on the time relationship between atrial and ventricular systole.

The more the intracardiac conductance was impaired, the more were disintegration of LV systole and visible reduction of LA compensation observed.

The presence of LBBB was not associated with any LAA systolic function deterioration (in contrast to the LA systolic function). In group I LAA planimetric parameters describing its size had the highest values among the study groups: LAA long., LAA area max., $L A A_{\text {area min., }} F_{L A A}$. Also Doppler parameters had the highest values in group I. LAAE was higher only in the patients in group IV - individuals who had MI with no conduction disturbances.

There was not observed any harmful haemodynamic effect of BBBs on LAA systolic function. All LAA parameters indicated LAA systolic function enhancement; this was the case also in patients with post-MI LBBB. In this group the LAA systolic function was the most enhanced.

The LAA is a highly autonomic chamber that differs in many aspects from the LA. The LAA has quite distinct anatomy and physiology from the LA $[47,49]$. The LAA contractile pattern differs from that of the main LA body [50]. The LAA shortens to a greater extent and it is also more distensible than the body of the LA [51-54]. This autonomy and the physiological differences between the LAA and the LA might explain why the LAA reacts differently than the LA to BBBs.

Our study tries to explain the role that the LA and LAA plays in the pathophysiology of the heart. The results of our study suggest how the cooperation between the LV, LA and LAA occurs after MI complicated with BBBs. The pattern of cooperation between the LV, LA and LAA might have an important impact on numerous clinical aspects such as physical activity, individual response to CRT, heart remodelling, and post-myocardial prognosis. 
LA remodelling after $\mathrm{MI}$ is associated with worse prognosis [55, 56]. Improvement of left atrial systolic function after CRT led to reverse LA remodelling expressed by reduction of LA size [57]. LA and LAA systolic function changes may help qualify patients for CRT.

Better and more precise description of the mutual interactions between heart chambers needs further studies including larger populations. Clinical trials are also necessary to define the exact role the LA and LAA play in heart pathology [58-61].

In conclusion, in patients who experienced MI, compensatory enhancement of systolic left atrial function is observed. Post-myocardial BBBs (mainly LBBB) are elements that reduce systolic left atrial function enhancement - the phenomenon that compensates post-myocardial left ventricular impairment. LA systolic function parameters seem to be more sensitive than LV systolic function parameters to heart overload. Post-myocardial LBBB do not affect systolic left atrial appendage function, in contrast to systolic left atrial function.

\section{References}

1. Das MK, Cheriparambil K, Bedi A, et al. Prolonged QRS duration (QRS $>/=170 \mathrm{~ms}$ ) and left axis deviation in the presence of left bundle branch block: A marker of poor left ventricular systolic function? Am Heart J 2001; 142: 756-9.

2. Skalidis El, Kochiadakis GE, Koukouraki SI, et al. Myocardial perfusion in patients with permanent ventricular pacing and normal coronary arteries. J Am Coll Cardiol 2001; 37: 124-9.

3. Kim WY, Sogaard P, Mortensen PT, et al. Three dimensional echocardiography documents haemodynamic improvement by biventricular pacing in patients with severe heart failure. Heart 2001; 85: 514-20.

4. Brikalis ES, Wright RS, Kopecky SL, Reeder GS, Williams BA, Miller WL. Bundle branch block as a predictor of longterm survival after acute myocardial infarction. Am J Cardiol 2001; 88: 205-9.

5. Melgarejo-Moreno A, Gacera-Tomas J, Garcia-Alberola A. Prognostic significance of bundle-branch block in acute myocardial infarction: the importance of location and time of appearance. Clin Cardiol 1998 2001; 24: 371-6.

6. Alegret JM, Marti V, Rodriguez FE, Alonso C, Guindo J, Dominguez-De-Rozas JM. Effects of thrombolysis in the evolution of right bundle branch block complicating an acute anterior myocardial infarction. Acta Cardiol 2001; 56: 297-301.

7. Baldasseroni S, Opasich C, Gorini M, et al. Left bundlebranch block is associated with increased 1-year sudden and total mortality rate in 5517 outpatients with congestive heart failure: a report from the Italian network on congestive heart failure. Am Heart J 2002; 143: 398-405.

8. Dissmann R, Kamke W, Reibis R, Herbstleb J, Wegscheider K, Völler H. Prognostic impact of left bundle-branch block in the early stable phase after acute myocardial infarction. Int J Cardiol 2008; 130: 438-43.
9. Ozdemir K, Altunkeser BB, Danis G, et al. Effect of the isolated left bundle branch block on sytemic and diastolic functions of left ventricle. J Am Soc Echocardiogr 2001; 14: 1075-9.

10. Vardas PE, Auricchio A, Blanc J, et al. Guidelines for cardiac pacing and cardiac resynchronization therapy. The Task Force for Cardiac Pacing and Cardiac Resynchronization Therapy of the European Society of Cardiology. Developed in Collaboration with the European Heart Rhythm Association. Eur Heart J 2007; 28: 2256-95.

11. Erol MK, Yilmaz M, Acikel M, Karakelleoglu S. Left atrial mechanical function in patients with essential hypertension. Acta Cardiol 2002; 57: 323-7.

12. Miyaguchi K, Iwase M, Matsui $\mathrm{H}$, et al. Role of left atrial booster pump function in worsening course of congestive heart failure. Jpn Circ J 1992; 56: 509-17.

13. Kono T, Sabbah HN, Rosman H, Alam M, Stein PD, Goldstein S. Left atrial contribution to ventricular filling during the course of evolving heart failure. Circulation 1992; 86: 1317-22.

14. Matsuda Y, Toma Y, Ogawa H, et al. Importance of left atrial function in patients with myocardial infarction. Circulation 1983; 67: 566-71.

15. Kizer JR, Bella JN, Palmieri V, et al. Left atrial diameter as an independent predictor of first clinical cardiovascular events in middle-aged and elderly adults: The Strong Heart Study. Am Heart J 2006; 151: 412-8.

16. Gerdts E, Wachtell K, Omvik P, et al. Left atrial size and risk of major cardiovascular events during antihypertensive treatment. Losartan Intervention for Endpoint in Hypertension Trial. Hypertension 2007; 49: 311-6.

17. Tsang TSM, Abhayaratna WP, Barnes ME, et al. Prediction of cardiovascular outcomes with left atrial size. J Am Coll Cardiol 2006; 47: 1018-23.

18. Abhayaratna WP, Seward JB, Appleton CP, et al. Left atrial size. Physiologic Determinants and clinical applications. J Am Coll Cardiol 2006; 47: 2357-63.

19. Douglas PS. The left atrium: a biomarker of chronic diastolic dysfunction and cardiovascular disease risk. J Am Coll Cardiol 2003; 42: 1206-7.

20. Beinart R, Boyko V, Schwammenthal E, et al. Long-term prognostic significance of left atrial volume in acute myocardial infarction. J Am Coll Cardiol 2004; 44: 327-34.

21. Moller JE, Hillis GS, Oh JK, et al. Left atrial volume: a powerful predictor of survival after acute myocardial infarction. Circulation 2003; 107: 2207-12.

22. Tang TS, Barnes ME, Gersh BJ, et al. Prediction of risk for first age-related cardiovascular events in an elderly population: the incremental value of echocardiography. J Am Coll Cardiol 2003; 42: 1199-205.

23. Lai HM, Aronow WS, Rachdev A, et al. Incidence of mortality in 1,040 patients with coronary heart disease or hypertensive heart disease with normal and abnormal left ventricular ejection fraction and with normal and abnormal QRS duration. Arch Med Sci 2008; 4: 140-2.

24. Yamaguchi M, Arakawa M, Tanaka T, Takaya T, Nagano T, Hirakawa S. Study on left atrial contractile performance - participation of Frank-Starling mechanism. Jpn Circ J 1986; 254: 84-9.

25. Wang YP, Takenaka K, Sakamoto T, et al. Effects of volume loading, propranolol and heart rate changes on pump function and systolic time intervals of the left atrium in open-chest dogs. Acta Cardiol 1993; 48: 245-62.

26. Okamoto M, Tsubokura T, Tsuchioka Y, et al. Determinants of left atrial systolic time intervals - assessment by pulsed Doppler echocardiography. Jpn Circ J 1991; 55: 232-7. 
27. Tatli E, Aktoz M, Altun A. Do plasma leptin levels predict diastolic dysfunction in patients with hypertension? Arch Med Sci 2009; 5: 342-6.

28. Hondo T, Okamoto M, Kawagoe T, et al. Effects of volume loading on pulmonary venous flow and its relation to left atrial functions. Jpn Circ J 1997; 61: 1015-20.

29. Keren G, Sherez J, Megidish R, Levitt B, Laniado S. Pulmonary venous flow pattern - its relationship to cardiac dynamics - a pulsed Doppler echocardiographic study. Circulation 1985; 71: 1105-12.

30. Gentile F, Mantero A, Lippolis A, et al. Pulmonary venous flow velocity pattern in 143 normal subjects aged 20 to 80 years old. Eur Heart J 1997; 18: 148-64.

31. Mantero A, Gentile F, Gualtierotti C, et al. Left ventricular diastolic parameters in 288 normal subjects from 20 to 80 years old. Eur Heart J 1995; 16: 94-105.

32. Mugge A, Kuhn H, Nikutta P, Grote J, Lopez AG, Daniel WG. Assesment of left atrial appendage function by biplane transesophageal echocardiography in patients with nonrheumatic atrial fibrillation: Identification of subgroup of patients at increased embolic risk. J Am Coll Cardiol 1994; 23: 599-607.

33. Chan SK, Kannam JP, Douglas PS, Manning WJ. Multiplane tranesophageal Echocardiographic assessment of left atrial appendage anatomy and function. Am J Cardiol 1995; 76: 528-30.

34. Agmon Y, Khanheria BK, Gentile F, Seward JB. Echocardiographic assessment of the left atrial appendage. J Am Coll Cardiol 1999; 34: 1867-77.

35. Otto CM. Clinical Echocardiography. WB Saunders Company, Philadepia 2002.

36. Rahimtola SH, Ehsani A, Sinno MZ, Loeb HS, Rosen KM, Gunnar RM. Left atrial transport function in myocardial infarction - importance of its booster pump function. Am J Med 1975; 59: 686-94.

37. Prioli A, Marino P, Lanzoni L, Zardini P. Increasing degrees of left ventricular filling impairement modulate left atrial function in humans. Am J Cardiol 1998; 82: 756-61.

38. Nonogi $\mathrm{H}$, Kawase $\mathrm{Y}$, Miyazaki S, Haze K, Hiramori K. Assessment of left ventricular filling dynamics utilizing Doppler echocardiography in acute coronary syndrome. Jpn Heart J 1994; 35: 163-73.

39. Olasińska-Wiśniewska A, Mularek-Kubzdela T, Seniuk W. Prognostic value of decreased heart rate variability in long-term follow-up in patients with acute myocardial infarction treated with thrombolysis. Arch Med Sci 2009; 5: 97-102.

40. Wiggers CJ, Katz LN. The contours of the ventricular volume curves under different conditions. Am J Physiol 1922; 58: 439-45.

41. Bavelaar-Croon CD, Wahba F, Van-Hecke MV, et al. Perfusion and functional abnormalities outside the septal region in patients in patients with left bundle branch block assessed with gated SPECT. Q I Nucl Med 2001; 45: 108-14.

42. Gesell RA. The effects of change in auricular tone and amplitude of auricular systole on ventricular output. Am J Physiol 1915; 38: 404-10.

43. Blinks JR. A method for study of the contraction of isolated heart muscle under various physical conditions. Circ Res 1961; 9: 342-9.

44. Braunwald E, Frahm CJ. Studies on Starling's Law of the heart IV. Observations on the hemodynamic functions of the left atrium in man. Circulation 1961; 24: 633-42.

45. Appleton CP, Galloway JM, Gonzales MS, Gaballa M, Basnight MA. Estimation of left ventricular filling pressures using two-dimensional and Doppler echocardiography in adult patients with cardiac disease. Additional value of analyzing left atrial size, left atrial ejection fraction and the difference in duration of pulmonary venous and mitral flow velocity at atrial contraction. J Am Coll Cardiol 1993; 22: 1972-82.

46. Hoit BD, Shao Y, Gabel M, Walsh RA. Left atrial mechanical and biochemical adaptation to pacing induced heart failure. Cardiovasc Res 1995; 29: 469-74.

47. Piotrowski G, Gawor R, Banach M, Piotrowska A, Rysz J, Gawor Z. High sensitivity C-reactive protein, NT-proBNP and hemodynamic left ventricular function in acute coronary syndrome without ST segment elevation a preliminary report. Med Sci Monit 2010; 16: CR313-317.

48. Pollick C, Taylor D. Assessment of left atrial appendqage function by transesophageal echocardiography. Implications for the development of thrombus. Circulation 1991; 84: 223-31.

49. Agmon Y, Khandheria BK, Meissner I, et al. Are left atrial appendage flow velocities adequate surrogates of global left atrial function? A population-based transthoracic and transesophageal echocardiographic study. J Am Soc Echocardiogr 2002; 15: 433-40.

50. Ito T, Suwa M, Kobashi A, Yagi H, Hirota Y, Kawamura K. Influence of altered loading conditions on left atrial appendage function in vivo. Am J Cardiol 1998; 81: 1056-9.

51. Hoit BD, Shao Y, Tsai LM, Patel R, Gabel M, Walsh RA. Altered left atrial compliance after atrial appendectomy. Influence on left atrial ventricular filling. Circ Res 1993; 72: $167-75$.

52. Hoit BD, Walsh R. Regional atrial distensibility. Am J Physiol 1992; 262: H1356-60.

53. Davis CA, Rembert JC, Greenfield JC. Compliance of left atrium with and without left atrium appendage. Am J Physiol 1990; 259: H1006-8.

54. Stöllberger C, Schneider B, Finsterer J. Elimination oft he Left atrial appendage to prevent stroke or embolism? Anatomic, physilogic, and pathophysiologic considerations. Chest 2003; 124: 2356-62.

55. Meris A, Amigoni $\mathrm{M}$, Uno $\mathrm{H}$, et al. Left atrial remodeling in patients with myocardial infarction complicated by heart failure, left ventricular dysfunction, or both: the VALIANT Echo study. Eur Heart J 2009; 30: 56-65.

56. Wierzbowska-Drabik K, Krzemińska-Pakuła M, Drożdż J, et al. Enlarged left atrium is a simple and strong predictor of poor prognosis in patients after myocardial infarction. Echocardiography 2008; 25: 27-35.

57. Yu CM, Fang F, Zhang Q, et al. Improvement of atrial function and atrial reverse remodeling after cardiac resynchronization therapy for heart failure. J Am Coll Cardiol 2007; 50: 778-85.

58. Piestrzeniewicz K, Łuczak K, Maciejewski M, Goch JH. Impact of obesity and adipokines on cardiac structure and function in men with first myocardial infarction. Arch Med Sci 2008; 4: 152-60.

59. Ruiz-Bailén M, Dolores Gallego de Guzmán M, RucabadoAguilar L, et al. Sustained ventricular arrhythmias in unstable angina patients: Results of the ARIAM Database. Med Sci Monit 2009; 15: CR280-9.

60. Goch A, Misiewicz P, Rysz J, Banach M. The clinical manifestation of myocardial infarction in elderly patients. Clin Cardiol 2009; 32: E46-51.

61. Kowalczyk M, Banach M, Mikhailidis DP, Hannam S, Rysz J. Ticagrelor - a new platelet aggregation inhibitor in patients with acute coronary syndromes. An improvement of other inhibitors? Med Sci Monit 2009; 15: MS24-30. 